\title{
PROYECTOS DE (DUDOSO) INTERÉS REGIONAL. INTROMISIÓN EN LA POLÍTICA MUNICIPAL DE VIVIENDA EN EXTREMADURA
}

\author{
Víctor Jiménez Barrado ${ }^{1}$ y Antonio-José Campesino Fernández \\ Departamento de Arte y Ciencias del Territorio. Universidad de Extremadura \\ victorjb@unex.es, acampesi@unex.es
}

\section{RESUMEN}

La mayoría de las legislaciones urbanísticas españolas considera los Proyectos de Interés Regional (PIR) como instrumentos de ordenación territorial, a caballo entre ésta y la ordenación urbanística encomendada a los planes generales, de competencia municipal. Amparándose en este carácter transfronterizo, la Administración regional extremeña ha utilizado los PIR como instrumento urbanístico para la promoción de su política pública de vivienda, a contrapelo de las competencias municipales en materia de planeamiento urbanístico y con intervenciones sin anestesia sobre el suelo no urbanizable.

Palabras clave: Proyectos de Interés Regional, planificación territorial, vivienda, ordenación urbana, Extremadura.

\section{ABSTRACT}

Most Spanish legislation considers urban Projects of Regional Interest as instruments of territorial management, halfway between it and the urban planning entrusted to the general plans of municipal jurisdiction. Relying on this cross-border character, the Government of Extremadura has used the PIR as planning instrument for the promotion of its public housing policy, against the municipal responsibility for urban planning and doing insensitive interventions on undeveloped land.

Keywords: Projects of Regional Interest, territorial planning, housing, urban development, Extremadura.

Fecha de recepción: enero 2015.

Fecha de aceptación: octubre 2015.

1 Esta investigación está financiada por el Ministerio de Educación, Cultura y Deporte, a través del Programa de Formación del Profesorado Universitario (FPU). Referencia FPU13/00990. 


\section{INTRODUCCIÓN}

Acertadamente, la previsión global de escenarios futuros ha mejorado la gestión del territorio. La planificación en cascada, que establece una prevalencia de la ordenación territorial sobre la urbanística, ha permitido el desarrollo conjunto de ciudades y territorios. La globalización ha provocado un abandono forzoso de la planificación localista, que empuja a poner en marcha nuevas formas estratégicas de gestión para aprovechar las sinergias existentes.

Si bien es cierto que las Administraciones han plasmado en sus legislaciones el propósito de organizar sus territorios acorde a esta línea, no lo es menos que la puesta en práctica ha resultado bastante defectuosa. En el caso de Extremadura, el proceso ha sido un rotundo fracaso. Las Directrices de Ordenación Territorial (DOT), fundamento de la organización territorial de la región, no han sido aún aprobadas. Tras casi 15 años desde la aprobación de la Ley 15/2001, de 14 de diciembre, del Suelo y Ordenación Territorial de Extremadura (LSOTEX), la región sigue huérfana de los cimientos de apoyo a los restantes instrumentos de planificación. Incomprensiblemente, el segundo peldaño de la ordenación territorial, los Planes Territoriales (PT), inició ya su andadura, aunque de forma exigua. La consecuencia es una organización del territorio fragmentada e inconexa, que atenta contra los valores intrínsecos de la planificación territorial y estratégica.

Los Proyectos de Interés Regional (PIR), de los que más adelante hablaremos con detenimiento, suponen el último peldaño de la planificación territorial en Extremadura. Sin embargo, su producción ha sido muy superior a la de los dos instrumentos anteriores. $\mathrm{Su}$ flexibilidad y un vertiginoso proceso de aprobación aumentan su operatividad. Esto demuestra, en nuestra opinión, que este instrumento se constituye como un cuerpo extraño en la planificación territorial. El parecido entre el objeto de los PIR y los Planes Parciales (PP), los asemejan a un instrumento de ordenación urbanística, con la ventaja añadida de prevalecer sobre los Planes Generales Municipales (PGM) o instrumentos análogos.

Una ventaja que en el caso de Extremadura se multiplica. El largo proceso de aprobación definitiva del planeamiento urbanístico lastra la economía y el desarrollo urbano de la región. De los 388 municipios extremeños sólo 51 cuentan con un Plan General Municipal adaptado a la LSOTEX, es decir, el 13,1 \% del total regional. Los restantes tienen vigentes instrumentos de planificación urbanística muy desfasados (Planes Generales de Ordenación Urbana, Normas Subsidiarias de Planeamiento y Proyectos de Delimitación del Suelo Urbano) que en el mejor de los casos datan de mediados de los noventa. Incluso un reducido número de municipios carece de cualquier figura de planificación urbanística ${ }^{2}$. Tal desconcierto obstaculiza sobremanera el desarrollo urbanístico de los municipios. En líneas generales, Extremadura tiene un planeamiento territorial prácticamente inexistente y un planeamiento urbanístico obsoleto. El crecimiento de las ciudades sólo se vio propiciado por la inyección de migraciones internas y el boom inmobiliario. En una región caracterizada por «mini-municipios menores de 1.000 habitantes que, suponiendo el 50,0\% del total, alojan aún al 10,0\% de los efectivos humanos regionales» (Campesino, 2010-2:562) es imposible pensar en un crecimiento urbano fundamentado en las previsiones demográficas. La demanda real de creación de ciudad no existió

2 Los municipios que carecen de planeamiento urbanístico municipal son Baños de Montemayor, Gargüera, Guadalupe, Valverde del Fresno y Villamiel. Además, las localidades de muy reciente creación todavía están a la espera de aprobar un instrumento de planeamiento urbanístico desvinculado e independiente del municipio-origen. 
durante el reciente periodo de expansión urbana, al menos de forma generalizada y en la magnitud desarrollada. La especulación urbanística propició un aumento del precio del suelo, hasta entonces desconocido, que desencadenó un incremento del precio de la vivienda. Ante la dificultad en la aprobación de una nueva generación de planes y la difícil gestión de los vigentes, la Administración regional optó por desarrollar política de vivienda pública a través de los PIR, a pesar de que el cometido inicial de este instrumento no fuera éste. De hecho, buena parte del segundo Plan Regional de Viviendas (Decreto 41/2004, de 5 de abril, por el que se aprueba el Plan de Vivienda y Suelo de Extremadura 2004-2007) y el Programa Especial de Vivienda (Plan 60.000) se hizo posible gracias a la figura de los PIR. Esta medida logró materializar de forma rápida y sencilla un volumen importante de viviendas públicas con gran demanda social ante el precio desbocado de la vivienda libre. Aprovechando su prevalencia, se pudo desbloquear el problema y ofrecer vivienda a un precio muy por debajo del que fijaba el mercado. Sin embargo, el abuso de los PIR como figura urbanística ha supuesto el menosprecio de «una herramienta fundamental que tienen los municipios para su desarrollo económico, social y medioambiental» (Jurado, 2010:278): el planeamiento urbanístico. La solución de urgencia adquirió visos de procedimiento habitual. El aterrizaje de estas figuras sobre la normativa urbanística municipal vigente nos obliga a reflexionar sobre el papel de ambos actores.

\section{REGULACIÓN Y USOS DE LOS PROYECTOS DE INTERÉS REGIONAL}

Los Proyectos de Interés Regional destacan entre los instrumentos de ordenación territorial por su practicidad y la concreción casi inmediata de sus propuestas. Sus características han permitido que sean una de las figuras más prolíficas del sector inmobiliario, incluso en tiempos de crisis. Siendo un «instrumento de planeamiento, legitima tanto la actuación como su inmediata ejecución» (Corchero, 2010:31). Su éxito se constata en el hecho de que diez de las diecisiete legislaciones autonómicas en materia de ordenación territorial recogen instrumentos (Tabla 1) que por su procedimiento de aprobación, características y objetivos se podrían considerar análogos a los PIR.

Cabe reseñar que aquellas Comunidades Autónomas con un mayor dinamismo urbanístico, al menos en el pasado reciente (Madrid, Cataluña, Comunidad Valenciana e Islas Baleares), carecen de este instrumento de planificación territorial en sus actuales legislaciones.

Como podemos observar, la nomenclatura es muy variada aunque existen elementos que permiten establecer equivalencias entre ellos. Prácticamente todos se ubican en el último peldaño de la escala territorial, prevaleciendo sobre la ordenación urbanística, pero supeditados a instrumentos destinados a una organización integral del territorio. La promoción y ejecución de los PIR o instrumentos análogos puede ser llevada a cabo por la Administración Pública, pero también por entes privados. A partir de aquí encontramos algunas diferencias como la clase y categoría de suelo sobre la que pueden desarrollarse. Tanto en Extremadura como en Castilla-La Mancha no existen restricciones en este aspecto, mientras que en Cantabria, Galicia y Murcia ${ }^{3}$ su desarrollo está prohibido en el SNU de Protección. En el caso

3 Artículo 46.2. Decreto Legislativo 1/2005, 10 junio, que aprueba el Texto Refundido de la Ley del Suelo de la Región de Murcia: Las Actuaciones de Interés Regional no podrán afectar a suelo no urbanizable de protección específica, salvo que su objeto sea garantizar esa protección, o sea compatible con ella. 


\begin{tabular}{|c|c|c|c|}
\hline CCAA & NOMENCLATURA & ARTÍCULADO & $\begin{array}{c}\text { USO } \\
\text { VIVIENDA }\end{array}$ \\
\hline Extremadura & $\begin{array}{c}\text { Proyectos de Interés } \\
\text { Regional }\end{array}$ & $\begin{array}{l}\text { Art. } 60-65 \text {. Ley } 15 / 2001 \text {, de } 14 \text { de } \\
\text { diciembre, del Suelo y Ordenación } \\
\text { Territorial de Extremadura. }\end{array}$ & Sí \\
\hline Aragón & $\begin{array}{l}\text { Proyectos de Interés } \\
\text { General de Aragón }\end{array}$ & $\begin{array}{c}\text { Art. 32-39. Ley 4/2009, de } 22 \text { de } \\
\text { junio, de Ordenación del Territorio. } \\
\text { de Aragón }\end{array}$ & Sí \\
\hline Canarias & $\begin{array}{l}\text { Proyectos de Actuación } \\
\text { Territorial (de gran } \\
\text { trascendencia territorial o } \\
\text { estratégica) }\end{array}$ & $\begin{array}{l}\text { Art. 25-27. Decreto Legislativo } \\
\text { 1/2000 } 8 \text { mayo, por el que se } \\
\text { aprueba el Texto Refundido de las } \\
\text { Leyes de Ordenación del Territorio } \\
\text { de Canarias y de Espacios Naturales } \\
\text { de Canarias. }\end{array}$ & No \\
\hline Cantabria & $\begin{array}{l}\text { Proyectos Singulares de } \\
\text { Interés Regional }\end{array}$ & $\begin{array}{l}\text { Art. 26-29. Ley 2/2001 } 25 \text { junio, de } \\
\text { Ordenación Territorial y Régimen } \\
\text { Urbanístico del Suelo de Cantabria. }\end{array}$ & Sí \\
\hline $\begin{array}{l}\text { Castilla-La } \\
\text { Mancha }\end{array}$ & Planes de Singular Interés & $\begin{array}{l}\text { Art. 18-23. Decreto legislativo } \\
\text { 1/2010, de } 18 \text { mayo, que aprueba } \\
\text { el Texto Refundido de la Ley de } \\
\text { Ordenación del Territorio y de la } \\
\text { Actividad Urbanística. }\end{array}$ & Sí \\
\hline $\begin{array}{l}\text { Castilla y } \\
\text { León }\end{array}$ & $\begin{array}{c}\text { Planes y Proyectos } \\
\text { Regionales }\end{array}$ & $\begin{array}{c}\text { Art. 20-25. Ley 10/1998, de } 5 \\
\text { de diciembre, de Ordenación del } \\
\text { Territorio de la Comunidad de } \\
\text { Castilla y León. }\end{array}$ & Sí \\
\hline Galicia & $\begin{array}{l}\text { Planes y Proyectos } \\
\text { Sectoriales de Incidencia } \\
\text { Supramunicipal }\end{array}$ & $\begin{array}{c}\text { Art. 22-25. Ley 10/1995, } 23 \\
\text { noviembre, de Ordenación del } \\
\text { Territorio de Galicia. }\end{array}$ & Sí \\
\hline La Rioja & $\begin{array}{l}\text { Proyectos de Interés } \\
\text { Supramunicipal }\end{array}$ & $\begin{array}{c}\text { Art. 34-37. Ley 5/2006, de } 2 \text { de } \\
\text { mayo, de Ordenación del Territorio } \\
\text { y Urbanismo. }\end{array}$ & No explícita \\
\hline Murcia & $\begin{array}{c}\text { Actuaciones de Interés } \\
\text { Regional }\end{array}$ & $\begin{array}{l}\text { Art. 41-47. Decreto Legislativo } \\
\text { 1/2005, } 10 \text { junio, que aprueba el } \\
\text { Texto Refundido de la Ley del Suelo } \\
\text { de la Región de Murcia. }\end{array}$ & Sí \\
\hline Navarra & $\begin{array}{l}\text { Planes y Proyectos } \\
\text { Sectoriales de Incidencia } \\
\text { Supramunicipal }\end{array}$ & $\begin{array}{c}\text { Art. 42-47. Ley Foral 35/2002, } \\
20 \text { diciembre, de Ordenación del } \\
\text { Territorio y Urbanismo. }\end{array}$ & Sí \\
\hline
\end{tabular}

Fuente: elaboración propia. 
de La Rioja, estas figuras pueden actuar sobre cualquier categoría de suelo a excepción del Suelo Urbanizable Delimitado. Las restantes CC.AA. no hacen referencia expresa a este punto en sus legislaciones.

Uno de los elementos diferenciadores, y clave en nuestra investigación, es la potencialidad de los PIR o instrumentos análogos para promocionar viviendas, y por lo tanto, intervenir directamente en la creación de ciudad desde una escala administrativa supramunicipal. A excepción de Islas Canarias, y la indefinición de La Rioja, todas las CC.AA. tienen capacidad de intervenir de manera directa en el desarrollo urbano (edificación de viviendas) de los municipios esgrimiendo un interés social.

Si nos centramos en el caso extremeño, el artículo 47 de la LSOTEX otorga a los PIR el rango de instrumento de ordenación del territorio, situándolos en el último escalafón del planeamiento territorial y, por lo tanto, prevalentes sobre la ordenación urbanística. La regulación de esta figura se encuentra contenida entre los artículos 60 y 65 de la mencionada Ley. Sin embargo, la redacción actual de los mismos proviene de la Ley 9/2010, de 18 de octubre, de Modificación de la LSOTEX.

Una de las principales ventajas de los PIR es que tienen una variada relación de objetos:

a) Infraestructuras de cualquier tipo, comprendiendo las construcciones e instalaciones complementarias precisas o adecuadas a su más completa y eficaz gestión o explotación.

b) Obras, construcciones o instalaciones, incluida la urbanización complementaria que precisen, que sirvan de soporte o sean precisas para la ejecución de la política o programación regional en materia de viviendas sujetas a algún régimen de protección pública, así como de dotaciones, equipamientos o establecimientos educativos, de ocio, salud, bienestar social, deporte o, en general, destinados a la provisión directa a los ciudadanos de bienes o prestaciones de naturaleza análoga.

c) Instalaciones para el desarrollo de actividades industriales y terciarias que tengan por objeto la producción, la distribución o la comercialización de bienes y servicios, tales como centros productivos de características especiales, que no tengan previsión ni acomodo en el planeamiento vigente.

d) Obras y servicios públicos y actuaciones conjuntas, concertadas o convenidas entre Administraciones Públicas o precisas, en todo caso, para el cumplimiento de tareas comunes o de competencias concurrentes, compartidas o complementarias.

e) Proyectos alejados de los núcleos urbanos en los que se promueva un desarrollo urbanístico asociado al fomento de intereses turísticos, de ocio, deportivos o similares.

Esta amplia relación de fines permite a los PIR «ordenar el territorio» mediante la construcción de importantes infraestructuras que darán servicio al conjunto de los extremeños, aunque la Ley también les concede la capacidad de intervenir en el desarrollo urbanístico de los municipios, a través de micro-proyectos tales como paquetes de vivienda pública. En ese momento, la escala territorial invade las competencias urbanísticas municipales aprovechando su prevalencia. Sin embargo, la ausencia de DOT y PT que plasmen y dirijan las estrategias y políticas regionales nos impiden conceptuar estas actuaciones (aun estando insertas en un plan regional de viviendas) dentro de una lógica territorial. 
Es básico comprender que la ordenación territorial y el urbanismo son conceptos distintos. Así se reconoce en la legislación, atribuyendo competencias entre las distintas escalas administrativas, según el objeto de los instrumentos. La consecución del desarrollo regional exige que ambos conceptos engarcen manteniendo nuestro modelo de planeamiento en escala, pero evitando solapar objetos y aptitudes.

En Extremadura, al igual que en otras muchas Comunidades Autónomas, existe una frontera difusa entre la planificación territorial y la urbanística. Prueba de ello es que la LSOTEX ha instaurado una discriminación positiva hacia los PIR en detrimento de los Planes Parciales (PP), siendo estos últimos los instrumentos idóneos para la creación de nueva ciudad. Esta ventaja se fundamenta en el proceso de aprobación de cada instrumento.

Desde el inicio, la ausencia u obsolescencia del planeamiento urbanístico genera una ventaja significativa favorable a los PIR. Este no es un tema baladí, mucho menos en Extremadura dónde, como ya vimos, la cantidad de planes adaptados a la LSOTEX es muy escasa y el ritmo de aprobación de nuevos PGM está anquilosado. El desarrollo de los PIR no está condicionado a la existencia de instrumentos urbanísticos, mientras que los PP, como instrumentos de desarrollo, no tienen razón de ser sin la aprobación de un Plan General Municipal y la existencia de suelo clasificado como urbanizable. La celeridad de los PIR se basa en este punto, ya que si comparamos la duración teórica del proceso de aprobación estipulado en la Ley de ambos instrumentos, resultan muy similares: tras la aprobación inicial del instrumento se abre un periodo mínimo de información pública de un mes en el Diario Oficial de Extremadura (DOE) y un diario no oficial de amplia difusión, que facultará a la Administración competente para emitir la aprobación definitiva.

En Extremadura, la experiencia en la tramitación de los PIR, al menos los referidos a la construcción de viviendas, nos arroja un tiempo medio de 167 días (aproximadamente 5,5 meses) transcurridos desde su aprobación inicial hasta la aprobación definitiva de los mismos. A esto, habría que sumar el tiempo acontecido entre la previa y obligada solicitud de «interés regional» y su aprobación (cercano a los 2 meses y medio).

El ámbito de aplicación de cada uno de los instrumentos también es un hecho diferenciador. Por un lado, los PP sólo pueden actuar en sectores completos del Suelo Urbanizable (SUB). Por otro, los PIR pueden ubicarse en cualquier clase y categoría de suelo, ya que tienen capacidad para cambiar la clasificación urbanística de los mismos.

El urbanismo moderno se construye a través de la figura del plan. El plan urbanístico analiza, prevé, ordena, clasifica y califica en función de las variables físicas, demográficas y económicas. Fruto de este trabajo resulta un modelo de desarrollo urbanístico acorde con los principios legales y las demandas locales. Mientras que la clasificación del Suelo Urbano (SU) atiende al cumplimiento de una serie de estándares urbanísticos y la clasificación y categorización del Suelo No Urbanizable (SNU) a la necesidad de proteger nuestro entorno, la clasificación del SUB se realiza en función de unas expectativas de crecimiento demográfico y económico que provocarán unas necesidades habitacionales futuras. El uso de los PIR en municipios que dispongan de SUB para desarrollar paquetes de vivienda quebranta este modelo. En defensa del plan, cabe recordar que la clasificación del suelo que realiza es discrecional pero no arbitraria, es decir, cada espacio clasificado lo está de acuerdo a una argumentación previa. 
Por último, debemos hacer hincapié en que las recientes reformas de la legislación urbanística y territorial constituyen un intento claro de extender las potencialidades de esta figura. Entre los cambios más relevantes podríamos citar:

- Capacidad de actuación sobre cualquier clase y categoría de suelo sin excepción, tenga o no planeamiento de desarrollo aprobado (artículo 60.1 LSOTEX). La anterior redacción impedía su aplicación sobre el Suelo No Urbanizable Protegido. En esta línea tendente a la desprotección de esta categoría de suelo se encuentra también la segunda modificación de la LSOTEX, Ley 9/2011, de 29 de marzo ${ }^{4}$.

- Necesidad de justificar «la insuficiencia del suelo con la clasificación y calificación idóneas» para desarrollar políticas públicas de vivienda, y además en el caso de viviendas de protección pública, «la existencia de un desequilibrio entre el número de demandantes, según datos oficiales, y el de las viviendas de estas características ofertadas en los cuatro años inmediatamente anteriores a la aprobación inicial del correspondiente Proyecto de Interés Regional». La ausencia de instrumentos adaptados a la LSOTEX propicia que en muchos municipios ni siquiera exista suelo clasificado como SUB, lo que beneficia claramente el desarrollo urbano a través de los PIR.

- Capacidad para acelerar la materialización de los programas de vivienda a través de los PIR «en el caso de existencia de suelo ya clasificado y con la calificación idónea suficiente para satisfacer la demanda de vivienda protegida» siempre que «habiendo practicado requerimiento al Municipio para que se lleve a cabo la ejecución del planeamiento, haya transcurrido sin efecto el plazo concedido al efecto» (artículo 60.2.b LSOTEX).

- Establecimiento de los PIR como herramientas de dinamización turística a través de macro-proyectos con uso residencial asociado (alojamientos turísticos residenciales susceptibles de venta a terceros). El germen de esta modificación legislativa ad hoc tuvo mucho que ver con la aprobación -con todas las bendiciones públicas gracias a un PIR- del Complejo Turístico Marina Isla de Valdecañas, sobre el que acaba de gravitar una sentencia de derribo del Tribunal Supremo, al haberse construido sobre un espacio protegido de la Red Natura 2000, delimitado por la misma Administración.

- Posibilidad de realizar adaptaciones a los PIR en su fase de ejecución (artículo 62.5 LSOTEX). La flexibilidad de este instrumento queda probada en este punto, siendo una ventaja cualitativa sobre los instrumentos urbanísticos.

En consecuencia, la figura de los PIR ha experimentado cambios con el fin de facilitar el desarrollo de la política de viviendas de Extremadura. Los esfuerzos de la Administración regional han ido dirigidos a promover de la forma más rápida y sencilla su oferta de vivienda pública. Una salida práctica de no ser porque no resuelve uno de los problemas crónicos

4 La redacción del artículo 11.3.1.b. LSOTEX en su descripción de valores necesarios para merecer la clasificación como Suelo No Urbanizable de Protección Ambiental expone que «la mera inclusión de unos terrenos en la Red Ecológica Natura 2000 no determinará, por sí sola, su clasificación como suelo no urbanizable, pudiendo ser objeto de una transformación urbanística compatible con la preservación de los valores ambientales necesarios para garantizar la integridad del área, y comprendiendo únicamente los actos de alteración del estado natural de los terrenos que expresamente se autoricen en el correspondiente procedimiento de evaluación ambiental». 
del urbanismo extremeño y nacional: el del planeamiento urbanístico municipal, realmente deficiente, incapaz de dar respuesta teórica y práctica a la pregunta de ¿Cómo redactar planeamiento urbanístico para mini-municipios regresivos?

\section{DESARROLLO DE LOS PIR EN EXTREMADURA. ESTUDIO DE CASOS}

Durante la última década, Extremadura ha desarrollado su política de vivienda en torno a la figura de los PIR. Los planes cuatrienales de promoción de vivienda pública han tomado como herramienta fundamental este instrumento de planificación territorial, en especial el Plan de Vivienda y Suelo de Extremadura 2004-2007. La región extremeña, desde la aprobación en 2001 de su marco regulador en materia de urbanismo y ordenación territorial, ha iniciado la tramitación de 44 PIR, de los cuales, diecinueve fueron concebidos con la finalidad de construir paquetes de vivienda pública. Si nos centramos única y exclusivamente en aquellos PIR con aprobación definitiva y cuyas determinaciones se han materializado total o parcialmente, es decir, aquellos que ya han iniciado sus obras y, en alguna medida, forman parte de la ciudad, el número disminuye hasta trece. Se demuestra así una clara vocación de este instrumento para incrementar la capacidad residencial de las ciudades a pesar de encontrarse en la escala de organización territorial. El resto de objetos se reparten entre la promoción industrial y la turística en enclaves singulares de la región.

El desarrollo edificatorio durante la «década prodigiosa del urbanismo español» fue desorbitado en algunos espacios de la geografía nacional, fundamentalmente en las grandes metrópolis y zonas litorales. En la región extremeña la construcción fue propiciada por la llegada coyuntural de emigrantes a las zonas de regadío y por los movimientos internos campo-ciudad.

Extremadura experimentó un lento, aunque progresivo, crecimiento de su población urbana. De 1996 a 2013, la población extremeña creció un 3,15\%, mientras que los residentes en ciudades de más de 20.000 habitantes aumentaron en un 5,6\% durante el mismo periodo. Hoy, 4 de cada 10 extremeños viven en estos núcleos, cifra aún muy por debajo de la tasa media de urbanización española (68\% del total). El gobierno autonómico dirigió sus políticas de vivienda, y en consecuencia los PIR, hacia los municipios más dinámicos: el denominado G-7 extremeño (Badajoz, Cáceres, Mérida, Plasencia, Don Benito, Almendralejo y Villanueva de la Serena ${ }^{5}$ ) y otras agrovillas con tendencias demográficas expansivas (Navalmoral de la Mata y Coria), así como pequeños pueblos favorecidos por la influencia de ciudades cercanas, como Arroyo de la Luz (hoy en descenso vegetativo) y Sierra de Fuentes, ambas en la periferia inmediata de la ciudad de Cáceres. De este modo, proveía de viviendas baratas a los enclaves dónde la construcción tenía una mayor actividad, para conseguir una estabilización de los precios.

Mientras que el inexorable proceso de despoblación rural se acrecentaba, el ritmo edificatorio en las ciudades extremeñas se incrementaba, propiciando una lucha por la propiedad del suelo que derivó en un aumento desmesurado del precio de la vivienda libre. El valor

5 Los PIR proyectados en los núcleos de Don Benito (PIR Vegas Altas) y Villanueva de la Serena (PIR Arenal de Santa Ana-Conquistadores) no llegaron a concretarse, por la anulación en el primer caso, y por el dilatado proceso de tramitación del mismo en el segundo. 


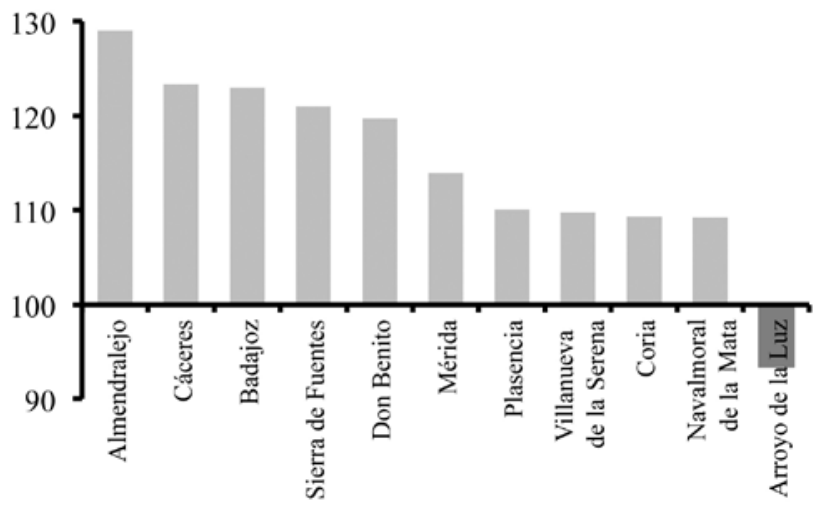

Fuente: Instituto Nacional de Estadística (2014). Elaboración propia.

medio del metro cuadrado construido de vivienda en Extremadura rondaba los $1.800 €$ en el primer trimestre de 2007 (punto álgido del boom inmobiliario), aproximadamente 600 euros/ metro cuadrado por encima de los valores del último trimestre de 2014 (según los datos del portal inmobiliario líder, Fotocasa). Ante estos precios, es fácil comprender la importancia de la vivienda pública, particularmente el Programa Especial 60.000, con un coste medio del metro cuadrado que rondaba los 750 euros. Por lo tanto, la política de vivienda pública se ajustó a los enclaves territoriales con mayor demanda y necesidad en ese periodo. El cuestionamiento de este análisis no se realiza tanto sobre el dónde, sino sobre el cuánto y cómo se llevaron a cabo dichas iniciativas.

La aplicación efectiva de los PIR dirigidos a la creación de viviendas públicas se produjo sobre nueve municipios, cuyo denominador común era la expansión demográfica. Sin embargo, su tamaño poblacional y características socioeconómicas distaban bastante. Si analizamos con detenimiento el estado del planeamiento urbanístico (lo que determinará posteriormente la gestión urbanística) de las poblaciones afectadas, podremos observar que el grado de actualización a la LSOTEX es sensiblemente superior a la media de Extremadura. Pese a ello, sólo un tercio de las localidades (Badajoz, Cáceres y Navalmoral de la Mata) contaban con un instrumento de planificación urbanística adaptado a la legislación vigente $^{6}$. Debemos remarcar que se trata de los municipios más importantes de la región y que, no obstante, su nivel de adaptación a la LSOTEX es muy insuficiente. En la tabla 2 se resume el tipo de figuras y la fecha de su aprobación definitiva, que además coincide en todos los casos con el instrumento vigente en el momento de aprobación definitiva de sus respectivos PIR.

6 En la actualidad, el municipio de Plasencia tiene vigente un PGM con aprobación definitiva el 15 de mayo de 2015 . 
Tabla 2

SINNTESIS MUNICIPAL DE LA FIGURA DE PLANEAMIENTO VIGENTE EN EL MOMENTO DE APROBACIÓN DEL PIR Y EL NDE VIVIENDAS PROYECTADAS

\begin{tabular}{|c|c|c|c|c|}
\hline Municipio & $\begin{array}{c}\text { Población } \\
\mathbf{( 2 0 1 3 )}\end{array}$ & $\begin{array}{c}\text { Instrumento } \\
\text { urbanístico } \\
\text { municipal }\end{array}$ & $\begin{array}{c}\text { Fecha Aprobación } \\
\text { Definitiva }\end{array}$ & $\begin{array}{c}\text { Número de } \\
\text { viviendas }\end{array}$ \\
\hline Almendralejo & 35.101 & PGOU & $16 / 02 / 1996$ & 626 \\
\hline Arroyo de la Luz & 6.206 & NNSS & $24 / 07 / 1996$ & 250 \\
\hline Badajoz & 150.621 & PGM & $07 / 11 / 2007$ & 4.390 \\
\hline Cáceres & 95.925 & PGM & $15 / 02 / 2010$ & 1.992 \\
\hline Coria & 13.010 & NNSS & $13 / 09 / 1989$ & 291 \\
\hline Mérida & 59.049 & PGOU & $19 / 07 / 2000$ & 1.114 \\
\hline Navalmoral de la Mata & 17.274 & PGM & $12 / 04 / 2005$ & 862 \\
\hline Plasencia & 41.047 & PGOU & $27 / 03 / 1996$ & 1.250 \\
\hline Sierra de Fuentes & 2.044 & NNSS & $29 / 05 / 2008$ & 295 \\
\hline
\end{tabular}

Fuente: Instituto Nacional de Estadística (2014) y Diario Oficial de Extremadura (Junta de Extremadura).15/05/2015. Elaboración propia.

Este contexto sigue condicionando y limitando un crecimiento urbanístico reglado acorde con los principios que la LSOTEX pretende aplicar en Extremadura. Un buen número de estos municipios se encuentran inmersos en un interminable proceso de aprobación de su planeamiento general, lo que impide actuar de forma rápida ante los cambios de coyuntura y las necesidades sobrevenidas. Los PIR se convirtieron en el instrumento perfecto para igualar la oferta y la demanda de vivienda pública durante la etapa de crecimiento económico.

Las actuaciones para la construcción de viviendas protegidas a través de los PIR en Extremadura han supuesto la promoción de 11.070 viviendas. En este aspecto, la ciudad de Badajoz tiene un peso destacado, ya que representa un 39,7\% del total, seguida de lejos por Cáceres, Plasencia y Mérida. Las cuatro ciudades más pobladas de Extremadura acogen 8 de cada 10 viviendas construidas, gracias a los PIR, dentro del Plan de Vivienda y Suelo de Extremadura 2004-2007.

Por tipologías ${ }^{7}$, el reparto se divide entre el Programa Especial $60.000(50,7 \%)$ que además está presente en mayor o menor medida en todos y cada uno de los PIR, el Régimen de Vivienda Media (43,5\%), sólo ausente en uno de ellos, y el Régimen General/Especial de Viviendas de Protección Oficial (5,8\%), sin representación en seis de los Proyectos.

7 Dos variables condicionan la distinción entre los tres regímenes de viviendas existentes: precio de venta máximo y superficie útil. El Programa Especial 60.000 (60.000€ por vivienda/60-80 metros cuadrados); el Régimen de Vivienda Media (909€ por metro cuadrado/100-110 metros cuadrados) y el Régimen General y Especial de Viviendas de Protección Oficial (subvencionable hasta el 20\% del precio de venta). 


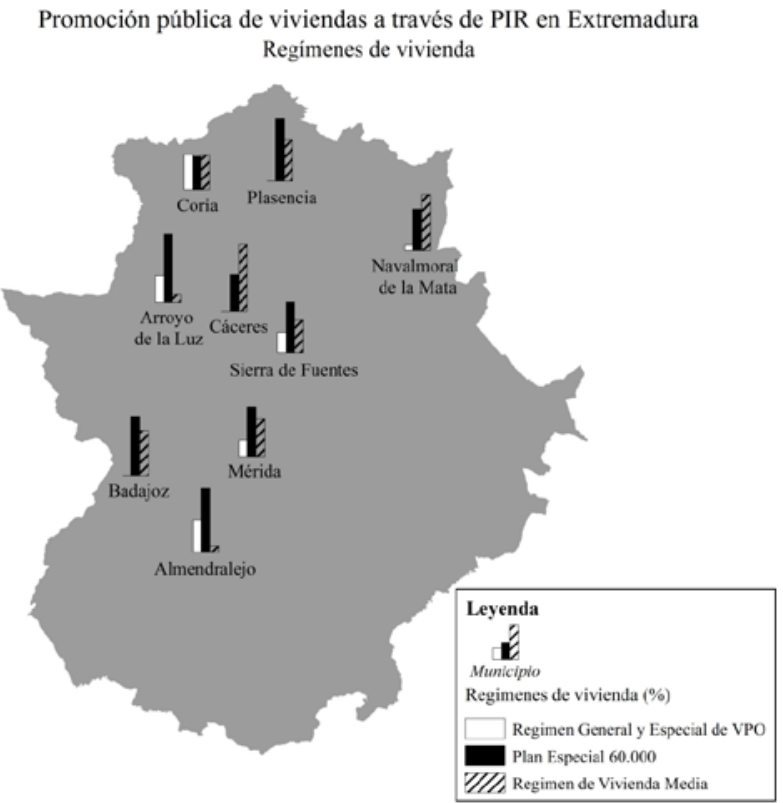

Fuente: Diario Oficial de Extremadura (Junta de Extremadura). Elaboración propia.

Para comprender la importancia del Programa Especial 60.000, cabe mencionar que en ocho de los trece proyectos ha significado el régimen de vivienda mayoritario, representando en siete de esos PIR un porcentaje superior al $50 \%$ del número total de viviendas.

El Régimen de Vivienda Media ha comandado en tres ocasiones estos paquetes de vivienda pública, representando siempre más de la mitad del número total de viviendas edificadas en dichas actuaciones.

Por último, sólo uno de los PIR realiza un reparto igualitario por número de viviendas entre los dos regímenes anteriores. El restante, realiza un reparto prácticamente idéntico entre los tres regímenes de vivienda, aunque dominado por el Régimen General de VPO.

Si centramos nuestra atención en el año de aprobación definitiva de los PIR, comprobamos que 2006 fue, con mucho, el más prolífico, tanto en número de instrumentos aprobados como de viviendas proyectadas en cada uno de ellos. Aunque la aprobación de PIR cae bruscamente el resto de años, caben destacar por número de viviendas proyectadas 2005 y 2007, gracias a las actuaciones aprobadas para la ciudad de Badajoz. Siguiendo esta lógica temporal realizaremos el estudio pormenorizado de casos.

La aprobación de los PIR, destinados a la construcción de vivienda pública, se inició el 26 de julio de 2005 con el denominado PIR Los Rostros-Cerro Gordo, que a la postre se convertiría en la actuación más importante por número de viviendas. Esta urbanización, constituye además la principal actuación del Programa Especial 60.000 (1.746 viviendas) y la segunda en cuanto al Programa de Vivienda Media (1.004 viviendas). 


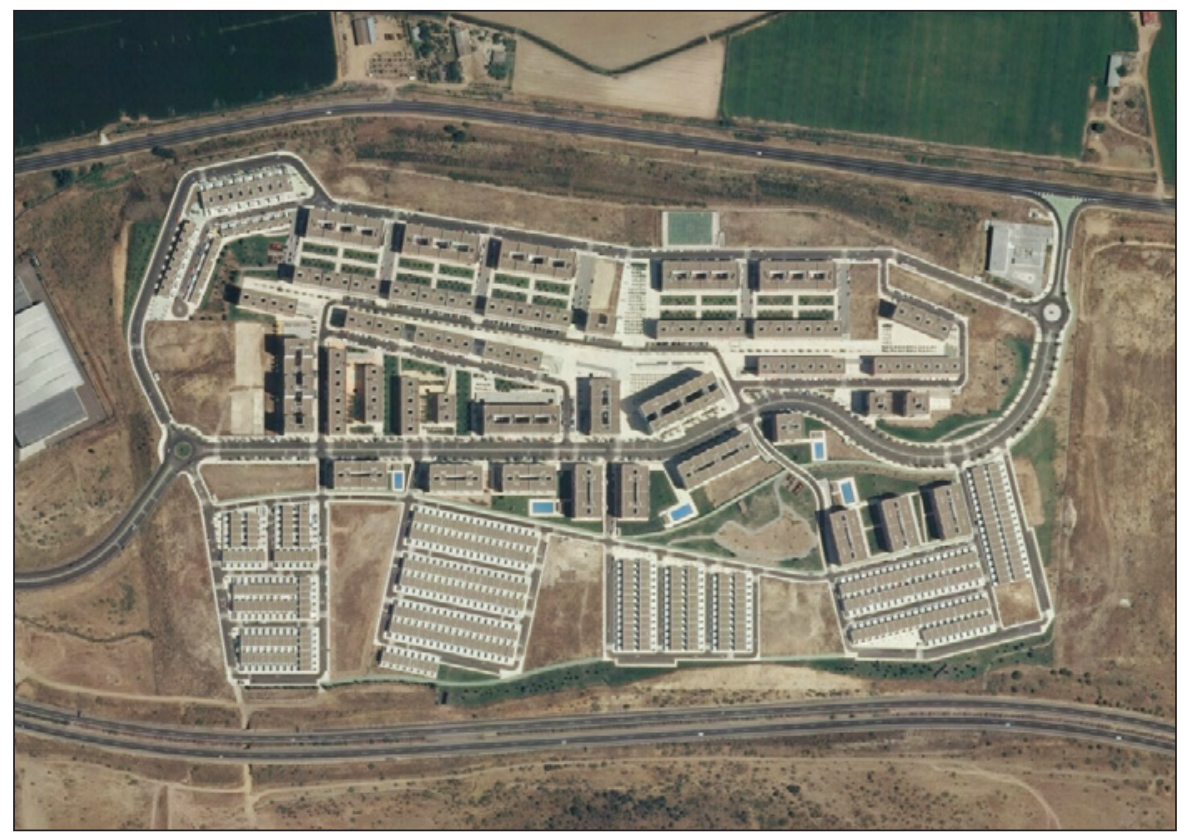

Fuente: Plan Nacional de Ortofotografía Aérea (2012). Centro Nacional de Información Geográfica.

Coincidiendo en fecha con la actuación anterior, se aprobó definitivamente el PIR La Calzada, ubicado en Mérida. Esta actuación, destacada por el alcalde de la ciudad como una apuesta de la Consejería por construir viviendas asequibles ${ }^{8}$, tiene una localización igualmente periférica. En ella, se contempló la edificación de 714 viviendas sobre una superficie bruta de $128.409 \mathrm{~m}^{2}$, de las que aproximadamente la mitad pertenecen al Programa Especial 60.000 (335), quedando el resto repartidas entre el Régimen de Vivienda Media (204) y el Régimen General de VPO (175).

También de forma simultánea, 4 de abril de 2006, se aprobaron los PIR Dehesa «Los Monjes» en Plasencia, PIR Entorno Estación Enológica y PIR Los Altos de Cantagallo, ambos localizados en la ciudad de Almendralejo. El primero de ellos constituye la promoción de vivienda pública más importante de la ciudad. En total 672 viviendas repartidas entre el Programa Especial 60.000 (429) y el Régimen de Vivienda Media (243) sobre una superficie bruta de $120.950,38 \mathrm{~m}^{2}$.

El PIR Entorno Estación Enológica, situado en el extremo sureste del municipio, es la actuación menos significativa de Extremadura por número de viviendas (202) y superficie bruta $\left(19.892 \mathrm{~m}^{2}\right)$. El régimen de viviendas está claramente decantado hacia el Plan Especial 60.000, con 132 viviendas por las 40 del Régimen de Vivienda Media y 30 de Régimen General. El PIR Los Altos de Cantagallo, formado por 424 viviendas, se ubica en el extremo

8 El Periódico Extremadura, 14 de noviembre de 2007. 


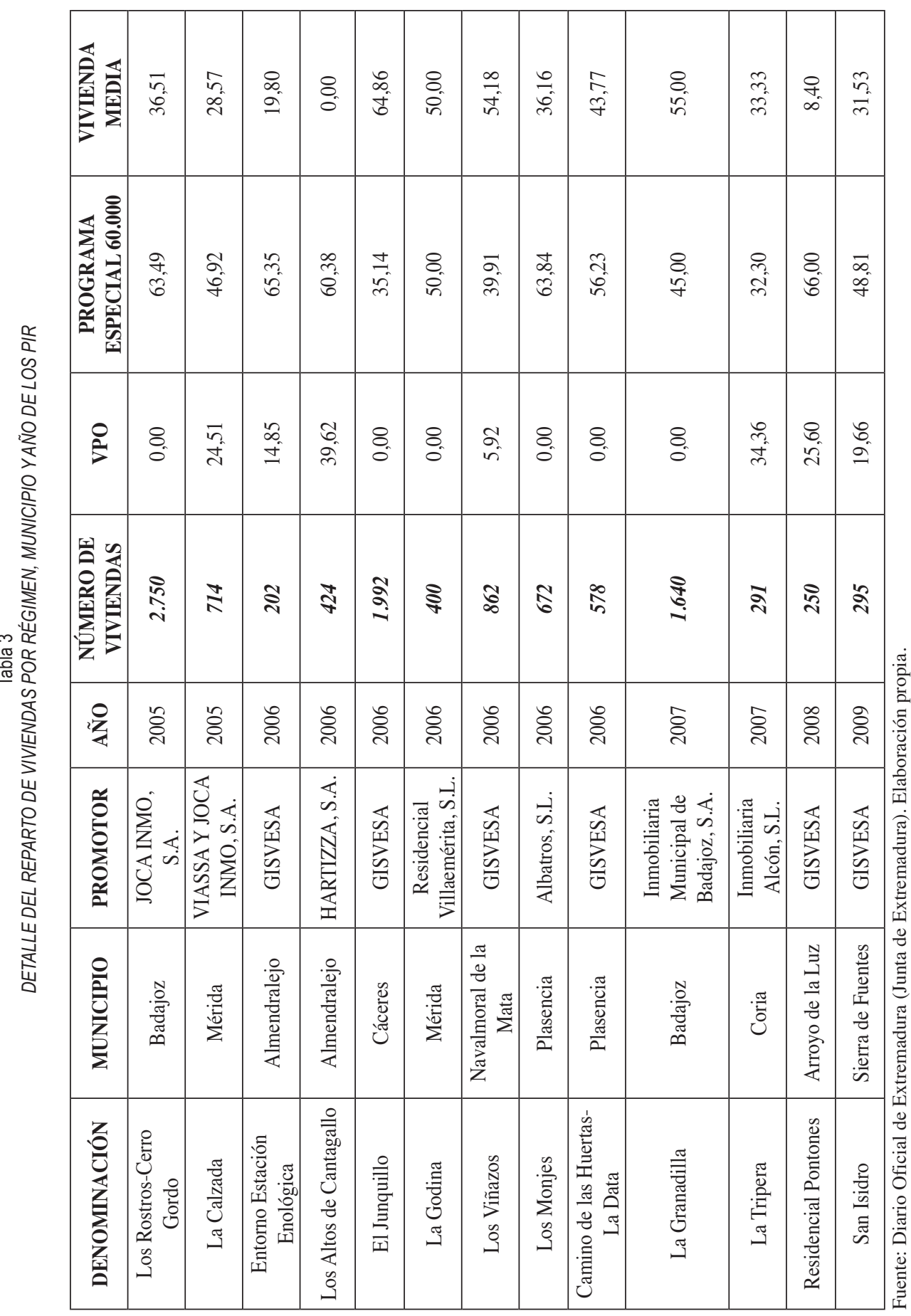


meridional del núcleo sobre una superficie bruta de 81.814,98 $\mathrm{m}^{2}$. En esta iniciativa, 6 de cada 10 viviendas pertenecen al Programa Especial 60.000, siendo las restantes VPO de Régimen General.

El 11 de julio de 2006, se produjo la aprobación definitiva de dos nuevos PIR. Por un lado, el segundo y último paquete destinado a promoción de vivienda pública en la capital extremeña. El PIR La Godina, ubicado al norte del núcleo urbano de Mérida, contempló la construcción de 400 viviendas, divididas a partes iguales entre los regímenes de Vivienda Media y del Plan Especial 60.000, sobre una superficie bruta de $77.790 \mathrm{~m}^{2}$.

Por otro lado, también el segundo y último proyecto localizado en Plasencia, el PIR Camino de las Huertas-La Data, constituido por 578 viviendas, repartidas entre las 325 del Plan Especial 60.000 y las 253 pertenecientes al Régimen de Vivienda Media, a desarrollar sobre una superficie bruta de 120.227 metros cuadrados.

La siguiente actuación, con aprobación fechada el 25 de julio de 2006, es el PIR El Junquillo, ubicado en Cáceres. Se trata del segundo paquete de vivienda pública más importante por superficie bruta $\left(332.190 \mathrm{~m}^{2}\right)$ y número de viviendas (1.992), situando a dicha ciudad como una de las principales beneficiarias del Plan de Viviendas 2004-2007, sólo superada por la capital pacense. El total de viviendas se reparte entre las 700 pertenecientes al Programa Especial 60.000 y las 1.292 en Régimen de Vivienda Media (principal actuación de este tipo en Extremadura).

Cerrando el año más prolífico, en cuanto aprobaciones definitivas de estos instrumentos, se encuentra el denominado PIR Los Viñazos (31 de julio). Supone la única actuación en materia de vivienda pública de la Junta de Extremadura en Navalmoral de la Mata. Prevé la construcción de 862 viviendas sobre una superficie bruta de 181.928,06 m². Por regímenes de vivienda, se reparten entre las 467 del Régimen de Vivienda Media, 344 del Plan Especial 60.000 y 51 del Régimen General de VPO.

La aprobación de los PIR destinados a vivienda pública durante el año 2007 se reduce a dos. En primer lugar, el PIR La Granadilla de Badajoz obtiene aprobación el 31 de agosto (Arrestizábal, 2006). Constituye la tercera actuación más importante por número de viviendas. Las 1.640 viviendas que lo componen se reparten entre las 738 del Programa Especial 60.000 y las 902 de Régimen de Vivienda Media, significando así la segunda y tercera mayor actuación en sus correspondientes regímenes, respectivamente.

El PIR La Tripera, aprobado definitivamente el 15 de octubre, es la única acción en materia de promoción de vivienda pública a través de los PIR en la ciudad de Coria. En él se proyecta la edificación de 291 viviendas sobre una superficie bruta de $64.246,6 \mathrm{~m}^{2}$. El reparto entre regímenes es muy parejo (100 Régimen General VPO, 94 del Programa Especial 60.000 y 97 del Régimen de Vivienda Media).

La actuación de la Junta de Extremadura en materia de vivienda pública desarrollada a través de PIR culminó en aquellos municipios de menor envergadura. En primer lugar, el PIR Residencial Pontones, aprobado el 25 de abril de 2008 y ubicado en Arroyo de la Luz. Por número de viviendas es la segunda menos importante, ya que sólo comprende la construcción de 250 viviendas, mayoritariamente incluidas en el Programa Especial 60.000 (165). El resto se reparten entre 64 en Régimen General de VPO y 21 en Régimen de Vivienda Media.

En último lugar, cerrando la política de vivienda pública de la Junta de Extremadura impulsada a través de esta figura, se encuentra el PIR San Isidro emplazado en Sierra de Fuentes y 
aprobado el 6 de marzo de 2009. En él se proyecta la construcción de 295 viviendas sobre una superficie bruta de $61.000 \mathrm{~m}^{2}$. Destaca la marcada importancia del Plan Especial 60.000 (144 viviendas) sobre el resto (93 Régimen de Vivienda Media y 58 de Régimen General de VPO).

Desde este último paquete de viviendas, la Junta de Extremadura ha frenado en seco el impulso y construcción de vivienda pública a través de PIR. Al Plan de Vivienda y Suelo de Extremadura 2004-2007, le han sucedido el Plan de Vivienda, Rehabilitación y Suelo de Extremadura 2009-2012 y el actual Plan de Rehabilitación y Vivienda de Extremadura 2013-2016. El cambio de escenario socioeconómico, en el que hemos pasado del desarrollismo urbano a un sector en decadencia y anquilosamiento se muestra en la propia nomenclatura de los planes.

La creación de nueva ciudad no es prioritaria debido a que el mercado no puede absorber un incremento del número de viviendas como años atrás. El sector ha virado hacia la rehabilitación edificatoria y la regeneración urbana ante la estrepitosa caída de ventas. Los problemas que plantearon los paquetes de vivienda promocionados a través de PIR (sobredimensionamiento de la oferta, desconexión con el centro ciudad, falta de liquidez y del flujo de crédito hipotecario, etc.) han obligado a cambiar de estrategia. Actualmente, la promoción de vivienda pública está mucho más atomizada, es decir, las actuaciones son mucho más pequeñas y repartidas por la geografía extremeña.

\section{INTROMISIÓN COMPETENCIAL Y DEFICIENCIAS DE LA POLÍTICA DE VIVIENDA PÚBLICA}

Los cuestionados PIR, lo son no por su fondo social defendible, sino por su forma de intervención indefendible -pese a la vuelta de tuerca de la LSOTEX y de su Reglamento de Planeamiento-, sobre las competencias urbanísticas y las decisiones legítimas de la Corporación Municipal, al pretender «hacer ciudad por cuenta ajena» a base de construir polígonos de viviendas, discrecionales (para unos promotores sí y para otros no), y masivos (resucitando el criticado «urbanismo de los polígonos» de los mejores años sesenta, aunque con firma ahora de arquitectos-estrella), sobre suelos no urbanizables de protección, que contravienen las directrices del Plan General Municipal y desajustan sus propuestas de ordenación urbana y territorial, ya aprobadas en Pleno (Campesino, 2007:14).

Estas actuaciones están ahora amparadas por una legislación regional que rompe, con la figura de los PIR, el equilibrio entre los subsistemas territorial y urbanístico. Sin embargo, la ejecución de algunas de estas iniciativas no ha llegado a materializarse, y cuando lo ha hecho, ha tenido que enfrentarse a diferentes problemáticas derivadas del contexto socioeconómico imperante que han condicionado su edificación y/o venta.

Si acudimos a la hemeroteca podemos encontrar multitud de ejemplos que delatan los fallos de esta política de viviendas. La perspectiva que nos otorga el paso de los años hace notorio el disparate que suponía la construcción de algunos PIR, como el de La Cantera de Olleta o El Muelo, ambos en Cáceres. El primero de ellos se podría tildar de auténtico despropósito urbanístico que contemplaba la edificación de unas 3.650 viviendas públicas (cifra rebajada sobre las 5.000 proyectadas inicialmente) sobre una cantera ilegal (suelo clasificado como No Urbanizable de Protección de Montaña) para el año 2016, y que finalmente no vio la luz. Un desarrollo urbanístico grandilocuente, incluso por su autoría, acompañado de grandes equipamientos (auditorio al aire libre con capacidad para 37.000 personas) que interrumpía el continuo urbano. 
Este último hecho, la «falta de conexión y continuidad con la trama urbana de Cáceres», fue uno de los motivos que el Tribunal Superior de Justicia de Extremadura argumentó, en su sentencia de 23 de julio de 2009, para justificar su negativa a la construcción del segundo PIR, un rechazo compartido por los responsables del consistorio municipal ${ }^{9}$. El macro-proyecto de El Muelo contemplaba la construcción de 3.986 viviendas sobre SNU incluido dentro de la Red Natura 2000. En la misma resolución, el magistrado resalta un hecho fundamental para entender los límites de la figura de los PIR, básico para mantener el equilibrio competencial entre las Administraciones:

«No desconocemos que un P.I.R. puede desarrollarse en cualquier clase de suelo y que permite modificar la clasificación y calificación urbanísticas de los terrenos a que afecta (artículos 60 y 61,1,j) Ley 15/2001) pero tampoco puede desconocerse que si un P.I.R. es contrario al planeamiento vigente, el examen de los requisitos del Proyecto y el cumplimiento de las finalidades previstas con el mismo deben examinarse de manera mucho más rigurosa, pues están en juego no sólo la compatibilidad con la ordenación urbanística en vigor sino también -lo que puede ser decisivo en muchos supuestos- las competencias municipales de elaboración y aprobación de los instrumentos de planeamiento».

La intromisión en las competencias municipales por parte del gobierno autonómico ha motivado otras sentencias similares del Tribunal Superior de Justicia de Extremadura. El PIR San Miguel, proyectado para la ciudad de Plasencia, también fue declarado nulo (Resolución de 20 de enero de 2009), ya que el órgano judicial estimó que la pretensión de la Administración regional superaba el interés social que suponía la construcción de vivienda pública. El PIR, que contenía la construcción de 599 viviendas, constituía realmente una modificación encubierta del PGOU y del PP vigente.

Estas actuaciones fallidas se identifican perfectamente con los sobredimensionados proyectos de la España neoliberal, al amparo de la Ley de Régimen del Suelo y Valoraciones de 1998. Sin embargo, otros proyectos sí llegaron a consumarse, como el ya mencionado PIR El Junquillo en Cáceres (Alonso, 2008). La previsión sobre la potencial demanda, que realizó la Junta de Extremadura, ha resultado a todas luces desproporcionada. Aún hoy, este gran paquete de vivienda pública todavía sin recepcionar, del que no se ha edificado ni la mitad de lo proyectado, cuenta con buena parte de ellas sin vender. La restricciones al crédito a particulares ha provocado un desplome en la venta de viviendas, que ha forzado la rectificación de la Administración. El objetivo del gobierno regional es modificar este PIR para aumentar el número de viviendas a edificar a cambio de una reducción de su superficie construida (y en consecuencia, su coste) y eliminar así, aquellas pertenecientes al Régimen de Vivienda Media. De este modo, se pretende dar salida a un proyecto en el que los primeros moradores se instalaron en el otoño de 2012 tras años de retraso. Sólo la movilización social, primero mediante la «Plataforma de Afectados por el Junquillo» y posteriormente la «Asociación de Vecinos 'El Junquillo'», ha permitido alcanzar «logros» tales como una parada del servicio de autobús urbano (situada en las afueras de la barriada sobre una Carre-

\footnotetext{
9 Diario Hoy, 15 de abril de 2008.
} 
tera Nacional) y un acceso peatonal (no contemplado en el proyecto inicial). No obstante, todavía persiste un sinfín de problemas derivados de su localización periférica, negada por el alcalde en aquel momento ("no rompe la ciudad") ${ }^{10}$, en origen clasificada como Suelo No Urbanizable Protegido (Protección Dehesa), y hoy límite occidental del Suelo Urbano de la ciudad. Esto ha derivado en enfrentamientos entre el Ayuntamiento cacereño y la Administración regional, plasmados en un informe técnico municipal que incluye más de 70 deficiencias con respecto a esta urbanización. Esta actuación supone uno de los mejores ejemplos para comprender la política de vivienda pública autonómica, promocionada a través de Proyectos de Interés Regional.

Si hablamos de sobredimensionamiento, no podemos obviar el PIR Los Rostros-Cerro Gordo de Badajoz (Timón, 2005), la actuación más importante por número de viviendas en Extremadura. Esta macroperación ubicada a 8 kilómetros del centro urbano, establece su conexión con el núcleo principal a través de la Carretera N-V o la Autovía A-5. Para llegar a comprender la magnitud de esta actuación aislada, basta decir que su capacidad de acogida representaba, en el momento de su aprobación, el 6,3\% de la población del municipio con más habitantes de Extremadura. Sin embargo, la ocupación real de este barrio a día de hoy es de 6.000 vecinos aproximadamente. Las principales reivindicaciones de los residentes vienen motivadas por su ubicación periférica y pasan por la mejora de servicios públicos, en especial la conexión entre la barriada y el núcleo urbano.

La promoción de vivienda pública debe atender a un interés social, por regla general de aquellos colectivos más necesitados. Por lo tanto, la Administración debe de hacer lo posible para adaptarse a esta demanda específica y tratar de optimizar el gasto. Sin embargo, la infrautilización de estos paquetes de vivienda se ha convertido en un hecho común. A los casos ya citados se unen las actuaciones realizadas en Almendralejo. Este municipio, que alberga dos proyectos (PIR Entorno Estación Enológica y PIR Los Altos de Cantagallo) registra uno de los mayores incrementos poblacionales de entre las localidades estudiadas. A pesar de ello, el éxito concreto de las promociones de vivienda pública en este núcleo urbano podría ponerse en tela de juicio a tenor de las informaciones aparecidas en la prensa regional:

La Crónica de Badajoz, 26 de enero de 2014:

«Las dos promociones más conocidas en Almendralejo son las de la Estación Enológica y los Altos de Cantagallo (...). Ambas terminadas desde hace seis años y con la mayoría de los pisos sin vender. Incluso en un bloque sólo hay dos inquilinos».

Sin embargo, existen otros proyectos que ponen de manifiesto la deriva que experimentó la Junta de Extremadura dentro del boom inmobiliario español. Ejemplo de ello son los PIR Los Viñazos (Navalmoral de la Mata) y Camino de las Huertas-La Data (Plasencia), ambos con sus obras de urbanización prácticamente completas (viario, acerado, mobiliario urbano, etc...), pero sin un solo bloque de edificios. En el primero de los casos, la paralización del proceso se debe a la incapacidad del mercado local para absorber tal cantidad de viviendas. La crisis económica y las restricciones del crédito a particulares han

10 El Periódico Extremadura, 8 de febrero de 2006. 
llevado a la Administración regional a posponer el inicio de la edificación de viviendas año tras año. El desarrollo de este proyecto sólo se plantea dividido en fases y, a tenor de la coyuntura económica, a muy largo plazo.

En el caso del PIR Camino de las Huertas-La Data, respaldado firmemente por el Ayuntamiento placentino ${ }^{11}$, las consecuencias han sido mucho más graves. Los beneficiarios de las mismas (desde mayo de 2008) son víctimas de una estafa cifrada en 3.000 euros por vivienda, correspondiente con la cantidad adelantada a la promotora, hoy en concurso de acreedores. La resolución de este problema supera la política de vivienda pública, puesto que actualmente pasa por la negociación entre la Administración regional y la «Plataforma de Afectados PIR La Data» para la concesión de viviendas por una cantidad que supera en $20.000 €$ el precio inicial.

En la misma línea, se encuentra el PIR Los Pontones de Arroyo de la Luz. Éste supone un desarrollo urbanístico sin precedentes para la población, debido a la envergadura de la actuación y al tamaño del municipio. Las obras de urbanización están completas, aunque la edificación de viviendas públicas sigue siendo tarea pendiente, a pesar de la existencia de algunas edificaciones aisladas de tipo unifamiliar en ese mismo entorno.

Figura 4

BLOQUES DE VIVIENDAS EN EL PIR «EL JUNQUILLO» (CÁCERES)

Y SOLARES SIN EDIFICAR DEL PIR «LOS VIÑAZOS» (NAVALMORAL DE LA MATA)
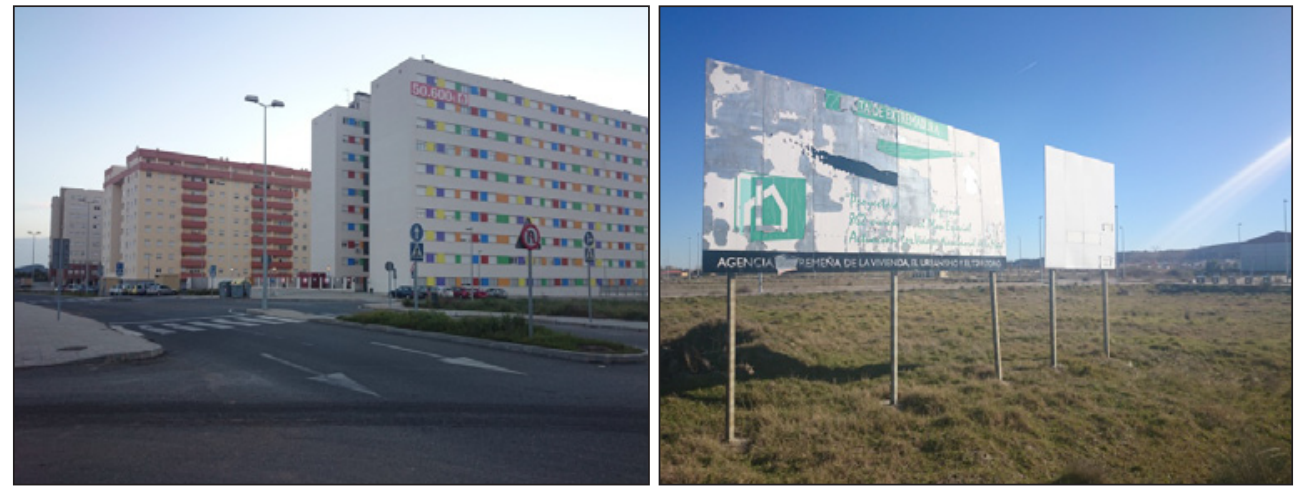

Elaboración propia.

En peor situación se encuentran los PIR La Tripera (Coria), San Isidro (Sierra de Fuentes) y La Granadilla (Badajoz). En todos los casos, los terrenos asociados carecen aún de urbanización. El único vestigio de estos proyectos lo podríamos encontrar, como en las dos actuaciones anteriores, en el solitario cartel anunciador de las mismas. En el último de los ejemplos, las dificultades para que los promotores (entre ellos la Inmobiliaria Municipal de Badajoz) consigan financiación han paralizado sine die un proyecto de 1.640 viviendas públicas, con una demanda que quintuplicaba la oferta.

11 El Periódico Extremadura, 4 de marzo de 2010. 
La crisis económica, unida a una falta de planificación y adaptación a las necesidades reales de vivienda pública, han propiciado el fracaso del Plan de Vivienda y Suelo de Extremadura 2004-2007. De las más de 11.000 viviendas proyectadas, apenas la mitad es una realidad. Por el contrario, los proyectos inacabados han contribuido a extender de forma inútil la superficie artificial de estos núcleos. La inversión realizada en la urbanización de estos proyectos difícilmente encontrará su rentabilidad en forma de edificación y moradores. El sobredimensionamiento de esta política de vivienda nos obliga a mirar a largo plazo, ya que para lograr que estos espacios se consoliden deberemos superar la recesión económica y en el caso de Extremadura, frenar la sangría demográfica por envejecimiento poblacional: misión imposible.

\section{CONCLUSIONES}

El desarrollo de la política de vivienda pública en Extremadura, a través de la figura de los Proyectos de Interés Regional, aun resultando innegables los beneficios que trajo consigo al mejorar las oportunidades de las personas, ha mostrado evidentes deficiencias. La confusión entre los objetos de la ordenación territorial y del urbanismo ha provocado el desconcierto a la hora de planificar nueva ciudad. La Administración regional, desde su capacidad para legislar en ambas materias, ha creado y modificado la legislación para poder ordenar el desarrollo urbanístico de sus municipios. En este proceso, ha obviado los principios del planeamiento urbanístico y de las competencias municipales, para imponer una «lógica» territorial, que tendría sentido si previamente hubiera desarrollado un esquema organizativo de modelo regional a través de las ausentes Directrices de Ordenación Territorial y de los Planes Territoriales.

Estas recientes modificaciones legislativas han permitido al gobierno autonómico actuar en solitario sobre el desarrollo urbano de sus municipios. La necesaria coordinación interadministrativa, en favor de una política de vivienda coherente, no ha tenido lugar. Además, los problemas acaecidos en el desarrollo de las actuaciones (demoras en los plazos, déficit de servicios y equipamientos, stocks de viviendas,...) han desembocado en protestas sociales, las cuales han derivado en no pocos enfrentamientos entre las corporaciones locales y la Junta de Extremadura.

Se puede afirmar, por tanto, que los paquetes edificados de vivienda pública responden más a actuaciones aisladas que a una política ordenada al servicio del interés social, confundiéndose el Interés Regional con el Interés Político ¿Cómo justificar si no actuaciones claramente incomunicadas y sobredimensionadas, que en el mejor de los casos han logrado, gracias a la lucha vecinal, casi equiparar su nivel de servicios y equipamientos al resto de barriadas de sus respectivos municipios? ¿Cómo justificar proyectos anulados por sentencias judiciales y otros tantos cuyas obras de urbanización han sido terminadas, pero carecen de viviendas edificadas? Las movilizaciones sociales ante casos de extrema gravedad, como las estafas urbanísticas acaecidas, dan muestra de la incapacidad del gobierno regional para gestionar el Plan de Vivienda y Suelo de Extremadura 2004-2007 a través de esta figura.

Por otro lado, los PIR de vivienda pública se han instalado, en buena medida, sobre el Suelo No Urbanizable de aquellos municipios con más dinamismo socioeconómico y demográfico. Es decir, aquéllos que mayor capacidad tienen para desarrollar por sí mismos un instrumento de planificación urbanística y, en consecuencia, crear sectores de Suelo Urbani- 
zable para desarrollar políticas de vivienda propia. De ello se desprende que el SNU para la Administración sigue teniendo un carácter residual, y no un valor fundamentado en la protección de elementos de diversa índole (agro-ganadera, ambiental, infraestructural, cultural,...). Esta manera de promover vivienda pública ha facilitado la paradoja de encontrar sectores del Suelo Urbanizable sin desarrollar, prácticamente contiguos a espacios del SNU dónde se han ubicado (que no completado) macro-urbanizaciones.

Los PIR han aterrizado a contrapelo sobre términos municipales previamente ordenados por el planeamiento, lo que ha conducido a desajustes en el modelo urbano propuesto con anterioridad. Los grandes paquetes de vivienda se encuentran aislados, inacabados, infrautilizados, como testigos de un tiempo pasado que siempre fue mejor para los especuladores, ejemplo del despilfarro de fondos públicos en época de bonanza.

Además, la preferencia por estos grandes municipios no ha hecho más que reforzar las tendencias de despoblación del medio rural extremeño. Aunque bien es cierto que la mayor demanda, atendiendo a las proyecciones demográficas, se realizaba sobre estos enclaves, no lo es menos que un reparto equilibrado de esta política podría haber fomentado el freno de este proceso. En aras de la optimización de recursos se optó por un modelo de concentración de la oferta, para atender a una gran demanda potencial. Unas previsiones realizadas en tiempos de desarrollo económico que auguraban un éxito rotundo de estas promociones, pero que una vez llegada la crisis acabaron en actuaciones inconclusas, viviendas vacías y barrios de segunda categoría.

Para concluir, es necesario poner de manifiesto que la presente concepción de los PIR, como instrumentos de ordenación territorial, encaja por su flexibilidad y capacidad de actuación en las necesidades de un mundo cambiante como el actual. Un instrumento fundamental para el desarrollo socioeconómico de cualquier región, ya que basa su razón de ser en su interés social. Sin embargo, su ilimitada arbitrariedad y mal entendida preponderancia sobre el planeamiento urbanístico municipal debe ser revisada. A tenor de lo expuesto, puede colegirse que el uso dado a esta figura por la Administración urbanística competente, dentro de la política de vivienda pública de Extremadura fue desmedido y no cumplió su objetivo de dudoso interés regional (al menos en el grado que cabía esperar).

\section{BIBLIOGRAFÍA}

ALONSO, A. (2008): «Sentencia del Tribunal Superior de Justicia de Extremadura sobre Proyecto de Interés Regional: 'El Junquillo de Cáceres'. Primeras impresiones». Revista de Derecho de Extremadura, no 2, 295-301.

ALONSO, A. (2009): «Sentencia del Tribunal Superior de Justicia de Extremadura sobre Proyecto de Interés Regional: 'El Pp3 de Plasencia'. Primeras impresiones». Revista de Derecho de Extremadura, $\mathrm{n}^{\circ}$ 4, 217-226.

ALONSO, A. (2010): «Los proyectos de interés regional en la jurisprudencia del TSJ de Extremadura». Práctica urbanística: Revista mensual de urbanismo, $\mathrm{n}^{\circ}$ 85, 20-21.

ARRESTIZÁBAL, A. (2006): Proyecto de Interés Regional 'La Granadilla'. Badajoz. Inmobiliaria Municipal de Badajoz.

CAMPESINO, A.-J. (2006): «Los PIR: intromisión en el municipio». El Periódico Extremadura, Cáceres. (1 de septiembre). 
CAMPESINO, A.-J. (2007): «El planeamiento cacereño o la «historia de un proceso imposible». BÓVEDA, Revista Oficial de la Federación Provincial de Empresarios de la Construcción, $\mathrm{n}^{\mathrm{o}} 26,14-15$.

CAMPESINO, A.-J. (2010-2): «Ordenación territorial de la Extremadura democrática». Cuadernos Geográficos, n 47, 553-581.

CAMPESINO, A.-J. y RENGIFO, J. I. (2010): Urbanismo y Patrimonio. Colección 19862008. Más de 20 años de progreso con Europa. Volumen 14. Badajoz. Junta de Extremadura, Fundación Universidad-Empresa, Red Extremeña de Información Europea (REINE).

CORCHERO, M. (2007): Derecho urbanístico de Extremadura. Tomo I: Planeamiento urbanístico. Cizur Menor. Editorial Thompson Aranzadi.

CORCHERO, M. (2008): Derecho urbanístico de Extremadura. Tomo II: Gestión urbanística. Cizur Menor. Editorial Thompson Aranzadi.

CORCHERO, M. (2010): Los Proyectos de Interés Regional (Apuntes, Legislación, Jurisprudencia y Bibliografía). Gata (Cáceres). Urbacorp.

CORCHERO, M. y SÁNCHEZ, L. (2014): «El control judicial del urbanismo de interés regional». Práctica urbanística: Revista mensual de urbanismo, $\mathrm{n}^{\circ}$ 128, 28-56.

INSTITUTO NACIONAL DE ESTADÍSTICA. (2014): Padrón municipal de habitantes. Disponible en http://www.ine.es/inebmenu/mnu_padron.htm, consultado el 4-2-2014.

JUNTA DE EXTREMADURA. (2001): Ley 15/2001, de 14 de diciembre, del Suelo y Ordenación Territorial de Extremadura. Mérida, Presidencia (DOE, 1, 03/01/2002 y BOE, 31 , 05/02/2002), 34-38.

JUNTA DE EXTREMADURA. (2004): Decreto 41/2004, de 5 de abril, por el que se aprueba el Plan de Vivienda y Suelo de Extremadura 2004-2007. Mérida, Consejería de Fomento (DOE, 1, 24/04/2004), 4697-4731.

JUNTA DE EXTREMADURA. (2006): Decreto 33/2006, de 21 de febrero, de modificación y adaptación del Plan de Vivienda y Suelo de Extremadura 2004-2007. Mérida, Consejería de Fomento (DOE, 1, 28/02/2006), 2985-3021.

JUNTA DE EXTREMADURA. (2007): Decreto 7/2007, de 23 de enero, por el que se aprueba el Reglamento de Planeamiento de Extremadura. Mérida, Presidencia (DOE, $\mathrm{n}^{\circ}$ 12, de 30/01/2007)., 1463-1466.

JUNTA DE EXTREMADURA. (2010): Ley 9/2010, de 18 de octubre, de modificación de la Ley 15/2001, de 14 de diciembre, del Suelo y Ordenación Territorial de Extremadura. Mérida, Presidencia (DOE nº 202 (20/10/2010), 24641-24645.

JURADO, J.M. (2010-2): «El vilipendiado urbanismo: una visión desde la experiencia en la gestión pública». Cuadernos Geográficos, n 47, 275-295.

MERINO, P. (2008): Proyectos de Singular Interés Regional y Evaluación Ambiental: ejemplos conforme a la legislación cántabra. Madrid. Editorial Dyckinson.

OLEA, W. (2008): «La ejecución de los Proyectos de Interés Regional» en Derecho urbanístico de Extremadura. Tomo II: Gestión urbanística (Corchero Pérez, M., Dir.). Cizur Menor. Editorial Thompson Aranzadi, 633-648.

TIMÓN, J. (2005): Proyecto de Interés Regional 'Cerro Gordo'. Mérida. Consejería de Vivienda-Junta de Extremadura.

TIMÓN, J. (2007): Proyecto de Interés Regional 'Cuartón Cortijo'. Mérida. Consejería de Vivienda-Junta de Extremadura. 
